Supplement of Hydrol. Earth Syst. Sci., 22, 305-316, 2018

https://doi.org/10.5194/hess-22-305-2018-supplement

(C) Author(s) 2018. This work is distributed under

the Creative Commons Attribution 3.0 License.

(c) (1)

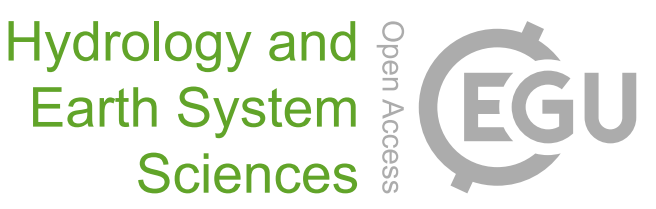

Supplement of

\title{
Impacts of future climate change on urban flood volumes in Hohhot in northern China: benefits of climate change mitigation and adaptations
}

Qianqian Zhou et al.

Correspondence to: Guoyong Leng (guoyong.leng@ouce.ox.ac.uk)

The copyright of individual parts of the supplement might differ from the CC BY 3.0 License. 


\section{Supplementary Materials}

Table S1: Infiltration parameters for three categories of soil in the SWMM simulation

\begin{tabular}{l|c|c|c|c}
\hline \multirow{2}{*}{ Soil category } & \multicolumn{4}{|c}{ Infiltration parameters } \\
\cline { 2 - 5 } & MaxRate & MinRate & Decay rate & DryTime \\
\cline { 2 - 5 } & {$[\mathrm{in} / \mathrm{hr}]$} & {$[\mathrm{in} / \mathrm{hr}]$} & {$[1 / \mathrm{hr}]$} & {$[$ days] } \\
\hline Dry loam with little or no vegetation & 3 & 0.5 & 4 & 7 \\
\hline Dry sand with little or no vegetation & 5 & 0.7 & 5 & 5 \\
\hline Dry clay with little or no vegetation & 1 & 0.3 & 3 & 9 \\
\hline
\end{tabular}

29

30

31

32

33

\section{Estimation of rainfall inputs based on the regional storm intensity formula (SIF):}

Application of the SIF is a standard practice for determining design rainfalls in urban drainage modelling in China, and is well documented in the National Guidance for Design of Outdoor Wastewater Engineering (MOHURD, 2011). In fact, the SIF represents an Intensity-DurationFrequency (IDF) relationship, which is a common approach in literature for estimating design rainfall hydrographs using the Chicago Design Storms (CDS) approach (Berggren et al., 2014; Willems et al., 2012; Zhou et al., 2013).

$$
\mathrm{q}=\frac{\mathrm{A}(1+\operatorname{Dlg}(\mathrm{P}))}{(\mathrm{t}+\mathrm{b})^{\mathrm{c}}}
$$

where $\mathrm{q}$ is the average rainfall intensity, and $\mathrm{P}$ and $\mathrm{t}$ are the design return period and duration of storm, respectively. The typical temporal resolution considered in SIF for urban drainage modelling is minutes. A, b, c, and D are regional parameters governing the IDF relationship among rainfall intensity, return period, and storm duration. For the study region, the values of A, b, c, and D were provided by the local weather bureau and well used in our previous studies (e.g., Zhou et al., 2016).

The procedure for applying SIF to obtain CDS is outlined in the National Technical Guidelines for Establishment of Intensity-Duration-Frequency Curve and Design Rainstorm Profile (MOHURD, 2014; Zhang et al., 2008; Zhang et al., 2015). Specifically, for a given return period, the SIF is fitted into the Horner's equation as:

$$
\mathrm{i}=\frac{\mathrm{a}}{(\mathrm{t}+\mathrm{b})^{\mathrm{c}}}
$$

Eq. S2 
50 The synthetic hyetograph based on the Chicago method is computed using Equation 2 and an 51 additional parameter $\mathrm{r}$ (where $0<\mathrm{r}<1$ ), which determines the relative time step of the peak 52 intensity, $t_{p}=r^{*}$. The time distribution of rainfall intensity is then described after the peak $t_{a}=(1-$ $53 \mathrm{r}$ ) ${ }^{*} \mathrm{t}$ and before the peak $t_{b}=r^{*} t$ using Equations 3 and 4 , respectively, where $i_{b}$ and $i_{a}$ are the 54 instantaneous rainfall intensity before and after the peak:

$$
\begin{aligned}
& i_{a}=\frac{a\left[\frac{(1-c) t_{a}}{(1-r)}+b\right]}{\left(\frac{t_{a}}{(1-r)}+b\right)^{1+c}} \\
& i_{b}=\frac{a\left[\frac{(1-c) t_{b}}{r}+b\right]}{\left(\frac{t_{b}}{r}+b\right)^{1+c}}
\end{aligned}
$$

55

56

57

58

59

60

61

62

63

64

65

66

67

68

69

70

71

72

73

74

75

76

77

78

79

80

\section{References}

Berggren, K., Packman, J., Ashley, R., and Viklander, M.: Climate changed rainfalls for urban drainage capacity assessment, Urban Water Journal, 11, 543-556, 10.1080/1573062X.2013.851709, 2014.

MOHURD: AQSIQ. Code for Design of Outdoor Wastewater Engineering (GB 50014-2006), Ministry of Housing and Urban-Rural Development, General Administration of Quality Supervision, Inspection and Quarantine of the People's Republic of China: Beijing, China (In Chinese), 2011.

MOHURD: Technical Guidelines for Establishment of Intensity-Duration-Frequency Curve and Design Rainstorm Profile (In Chinese), Ministry of Housing and Urban-Rural Development of the People's Republic of China and China Meteorological Administration, 2014.

Willems, P., Arnbjerg-Nielsen, K., Olsson, J., and Nguyen, V. T. V.: Climate change impact assessment on urban rainfall extremes and urban drainage: Methods and shortcomings, Atmospheric Research, 103, 106-118, 2012.

Zhang, Y.-q., Lv, M., and Wang, Q.-g.: Formula method design of drainage pipe network and analysis of model simulation, Water Resour. Power, 33, 105-107, 2015.

Zhang, D., Zhao, D. q., Chen, J. n., and Wang, H. z.: Application of Chicago approach in urban drainage network modeling, Water \& Wastewater Engineering, 34, 354-357, 2008.

Zhou, Q., Ren, Y., Xu, M., Han, N., and Wang, H.: Adaptation to urbanization impacts on drainage in the city of Hohhot, China, Water Science and Technology, 73, 167-175, 10.2166/wst.2015.478, 2016.

Zhou, Q., Panduro, T., Thorsen, B., and Arnbjerg-Nielsen, K.: Adaption to Extreme Rainfall with Open Urban Drainage System: An Integrated Hydrological Cost-Benefit Analysis, Environmental Management, 51, 586-601, 2013. 